\title{
PERDAS DE FÓSFORO E POTÁSSIO POR EROSÃO HÍDRICA EM UM INCEPTISOL SOB CHUVA NATURAL ${ }^{(1)}$
}

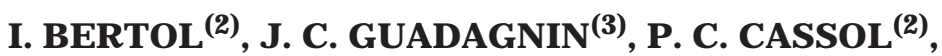 \\ A. J . AMARAL ${ }^{(4)} \&$ F.T. BARBOSA ${ }^{(4)}$
}

\begin{abstract}
RESUMO
Sistemas inadequados de manejo do solo favorecem a erosão hídrica, perdas de nutrientes e poluição das águas superficiais, acelerando a degradação ambiental. As perdas de P e K por erosão hídrica foram avaliadas entre 1999 e 2001, em um Cambissolo Húmico alumínico léptico com $0,102 \mathrm{~m} \mathrm{~m}^{-1} \mathrm{de}$ declividade, em Lages (SC), sob condições de chuva natural, em diferentes sistemas de manejo do solo. Os tratamentos de preparo do solo foram: semeadura direta em seis anos $\left(S D I_{6}\right)$, semeadura direta em nove anos (SDIg), escarificação + gradagem em nove anos $\left(E+G_{9}\right)$ e aração + duas gradagens em nove anos $\left(A+2 G_{g}\right)$, cada um com duas parcelas experimentais, sendo uma parcela submetida à rotação das culturas de feijão, ervilhaca, milho e aveia e a outra, à sucessão de soja, trigo, soja e trigo, além de um tratamento-testemunha, constituído por aração + duas gradagens sem cultivo, em nove anos (SSC g $_{9}$. O P e o $\mathrm{K}$ foram determinados tanto na água quanto nos sedimentos da enxurrada. As concentrações dos dois elementos foram maiores nos sedimentos do que na água da enxurrada. Tanto na água quanto nos sedimentos da enxurrada, os preparos de solo conservacionistas proporcionaram maiores concentrações de $\mathrm{P}$ e K do que os preparos de solo convencionais. As perdas totais de $\mathrm{K}$ foram maiores na água do que nos sedimentos da enxurrada, com exceção do manejo $\mathrm{SSC}_{9}$. Com relação às perdas de $\mathrm{P}$, apenas nos manejos $\mathrm{SDI}_{6}$ e $\mathrm{SDI}_{9}$ elas foram maiores na água do que nos sedimentos. No caso da água da enxurrada, as perdas totais de $\mathbf{P}$ foram maiores nos manejos $\mathrm{SDI}_{6}$ e $\mathrm{SDI}_{9}$, enquanto as de $\mathrm{K}$ variaram com os preparos conservacionistas e convencionais, sem apresentarem tendência clara. No caso do sedimento da enxurrada, as perdas totais de $\mathrm{K}$ foram menores nos preparos conservacionistas, mas as de $\mathbf{P}$ foram menores apenas nos manejos $\mathrm{SDI}_{6}$ e SDI 9 .
\end{abstract}

Termos de indexação: perdas de solo, perdas de água, perdas de nutrientes, preparo conservacionista.

\footnotetext{
(1) Parte da Tese de Mestrado do segundo autor. Desenvolvido com recursos do CNPq/FINEP/CAPES e Universidade do Estado de Santa Catarina - UDESC. Recebido para publicação em junho de 2003 e aprovado em março de 2004.

(2) Professor do Centro de Ciências Agroveterinárias, Universidade do Estado de Santa Catarina - UDESC. Caixa Postal 281, CEP 88520-000 Lages (SC). Bolsista do CNPq. E-mail: a2ib@cav.udesc.br.

(3) Pós-Graduando em Agronomia, Centro de Ciências Agroveterinárias, UDESC. Bolsista da CAPES.

(4) Aluno da Faculdade de Agronomia, UDESC. Bolsista de Iniciação Científica PIBIC.
} 


\title{
SUMMARY: PHOSPHORUS AND POTASSIUM LOSSES BY WATER EROSION IN AN INCEPTISOL UNDER NATURAL RAINFALL
}

\begin{abstract}
I nadequate soil management systems can lead to water erosion, nutrient losses and superficial water pollution, accelerating environmental degradation. The $\mathrm{P}$ and $\mathrm{K}$ losses caused by water erosion wereevaluated from November 1999 to October 2001 in an Inceptisol with $0.102 \mathrm{~m} \mathrm{~m}^{-1}$ slope, in Lages, Santa Catarina State, Brazil, under natural rainfall conditions. Theevaluated soil management systems were: no-tillagefor six years ( $\mathrm{NT}_{6}$ ), notillagefor nine years $\left(\mathrm{NT}_{9}\right)$, chiseling plus one disking for nineyears $\left(\mathrm{C}+\mathrm{D}_{9}\right)$, and pl owing plus disking twicefor nineyears $\left(\mathrm{P}+\mathrm{D}_{9}\right)$. All of thesetreatments werecarried out in duplicate One experimental plot was cultivated with bean, vetch, corn, and oat in rotation, and the other with soybean, wheat, soybean, and wheat in succession. An additional treatment consisted of bare soil (control), which was periodically tilled with plowing plus disking twice for nine years $\left(\mathrm{BS}_{9}\right)$. The $\mathrm{P}$ and $\mathrm{K}$ contents were determined in runoff water and sediments. Both $\mathrm{P}$ and $\mathrm{K}$ concentrations were higher in runoff water and sediments under theconservation soil tillagethan under conventional soil tillage. Total $\mathrm{K}$ losses werehigher in the runoff water than in the sediment, except in the $\mathrm{BS}_{9}$ treatment. Regarding $\mathrm{P}$ losses, they were higher in water than sediment only in the $\mathrm{NT}_{6}$ and $\mathrm{NT}_{9}$ tillage. In the runoff water, thetotal $\mathrm{P}$ losses were higher in $\mathrm{NT}_{6}$ and $\mathrm{NT}_{9}$ tillage, while the $\mathrm{K}$ losses varied with conservational tillageand conventional tillage, with no clear trend. Potassium losses in the runoff sediment weresmaller in conservational tillage, but those of $\mathrm{P}$ were only smaller in $\mathrm{NT}_{6}$ and $\mathrm{NT}_{9}$ treatments.
\end{abstract}

Index terms: soil losses, water losses, nutrient losses, conservation tillage

\section{INTRODUÇÃO}

As perdas de nutrientes por erosão hídrica são influenciadas pela sua concentração na água e nos sedimentos e pela perda total de água e de sedimentos por erosão (Schick et al., 2000b; Favaretto, 2002; Guadagnin, 2003; Bertol et al., 2003). A concentração de nutrientes na água e nos sedimentos, por outro lado, varia com sua concentração no solo (Daniel et al., 1994; F avaretto, 2002), a qual é influenciada pelas adubações e pela cobertura e manejo do solo (Seganfredo et al., 1997; Schick et al., 2000b; Mello, 2002).

Os preparos de solo conservacionistas caracterizam-se pela presença de maior rugosidade (exceto a semeadura direta) e cobertura superficial do que os convencionais (Cogo, 1981; Bertol, 1995; Schick et al., 2000a). Assim, as perdas de água e sedimentos são reduzidas nos sistemas conservacionistas, o que diminui as perdas totais de nutrientes por erosão nesses sistemas de manejo (Bertol , 1994a; King et al., 1996; Schick et al., 2000b).

A aplicação de adubos nas lavouras, durantelongo período de tempo, tende a aumentar a concentração de $\mathrm{P}$ e K na superfície do solo, especialmente na semeadura direta sem revolvimento do solo (Eltz et al., 1989; Schick et al., 2000b). I sto proporciona aumento das concentrações desses nutrientes tanto na água quanto nos sedimentos presentes na enxurrada (Pote et al., 1996; Schick et al., 2000b; Guadagnin, 2003). Mcl saac et al. (1995), aplicando $50 \mathrm{~kg} \mathrm{ha}^{-1}$ de $\mathrm{P}$ no cultivo da soja, obtiveram concentrações de $0,8 \mathrm{mg} \mathrm{L}^{-1}$ do elemento na água da enxurrada na semeadura direta e de $0,5 \mathrm{mg} \mathrm{L}^{-1}$ na água do cultivo mínimo, sob chuva simulada, nos primeiros 10 dias após a semeadura da cultura.

Trabalhando num Cambissol o Húmico álico, sob rotação de culturas, Bertol (1994a) verificou que as perdas totais deP foram maiores no solo sem cultivo (descoberto) do que no preparo convencional, cultivo mínimo e semeadura direta, enquanto as perdas totais de K não diferiram. A principal razão para esse comportamento, no caso do $\mathrm{P}$, foi a variação nas perdas de solo e água entre os tratamentos estudados, já que as concentrações do el emento foram maiores na semeadura direta do que nos demais tratamentos, especial mentenos sedimentos.

Em trabalho realizado por Guadagnin (2003), durante quatro cultivos, o autor observou que as perdas totais de $\mathrm{P}$ eK por erosão hídrica na água da enxurrada em geral diminuíram do início ao final do ciclo das culturas; no caso dos sedimentos, as referidas perdas em geral aumentaram do início ao final dos ciclos.

Emáreas submetidas a sistemas conservacionistas de manejo do solo e com adubação fosfatada, ocorrem, em geral, enxurradas com el evada concentração de P (Daniel et al., 1994). Nestes sistemas, nos quais ocorrem menores perdas totais de água e sedimentos por erosão hídrica do que nos preparos convencionais, as perdas totais de $\mathrm{P}$ em geral são menores, apesar da maior concentração desse el emento na superfície do solo nos preparos conservacionistas (Schick et al., 2000b). 
Hernani et al. (1999), quantificando as perdas denutrientes em diferentes sistemas demanejo num Latossolo Roxo, verificaram que, sob a sucessão trigo-soja, a semeadura direta foi otratamento mais eficaz no controle da erosão, possibilitando, comisso, menores perdas de $\mathrm{K}$ do que o sistema grade pesada + grade niveladora.

Trabalhando em sistemas de preparo de solo conservacionistas e convencionais, com rotação de culturas, Langdale et al. (1985) observaram pequenas perdas totais de $P$ na água da enxurrada, quando foram aplicados entre 20 e $50 \mathrm{~kg} \mathrm{ha}^{-1}$ desse el ementona semeadura. Esses autores encontraram correlação linear e positiva entre as perdas de sol o e de $P$ pela enxurrada, em preparos de solo conservacionistas e convencionais. Os referidos autores observaram, ainda, que, no preparo convencional, a maior parte do $\mathrm{P}$ perdido estava adsorvidoaos sedimentos da enxurrada. Nos preparos conservacionistas, por outro lado, como as perdas desedimentos foram baixas, as perdas totais de $\mathrm{P}$ por erosão hídrica foram expressivamente diminuídas em relação aos métodos de preparo convencionais.

Experimentos realizados por Daniel et al. (1994) e Schick et al. (2000b) indicaram que as concentrações de P na camada superficial do solo apresentaram correlação linear e positiva com as concentrações desse elemento nos sedimentos presentes nas águas de enxurrada. Poteet al . (1996) também observaram que doses crescentes de $P$ aplicado no solo correlacionaram-se linear e positivamente com os conseqüentes aumentos nas concentrações do elemento na água da enxurrada, resultando em aumentos das perdas totais desse elemento na erosão hídrica.

Embora o $\mathrm{P}$ solúvel na água represente uma pequena fração do $P$ total perdido por erosão hídrica, a forma solúvel desse el emento é mais prontamente biodisponível do que aquela ligada aos sedimentos (Mclsaac et al., 1995), razão por que pode causar impacto imediato nos locais de deposição, fora do local de origem da erosão.

O objetivo destetrabalho foi quantificar as perdas de P eK na água e nos sedimentos da erosão hídrica sob chuva natural, em diferentes sistemas de manejo de um Cambissolo Húmico alumínico léptico.

\section{MATERIAL E MÉTODOS}

O experimento foi realizado entre novembro de 1999 e outubro de 2001, na região do Planalto Sul Catarinense, situada a 27 여' 'de latitude Sul e 50 이 ' de longitude Oeste, a $937 \mathrm{~m}$ de altitude média, onde o clima é do tipo $\mathrm{Cfb}$, segundo a classificação de Köeppen, com precipitação média anual de $1.600 \mathrm{~mm}$. O sol o no local do experimento é um Cambissol o Húmico alumínico léptico argil oso horizonte A moderado, com substrato composto de siltitos +argilitos e declividademédia de 0,102 $\mathrm{m} \mathrm{m}^{-1}$, descrito em Bertol (1994b). Esta área experimental vem sendo utilizada desde novembro de 1988 para estudos de erosão hídrica sob chuva natural.

Os tratamentos de preparo do solo, distribuídos ao acaso, consistiram em: semeadura direta durante seis anos $\left(\mathrm{SDI}_{6}\right)$, semeadura direta durante nove anos $\left(\mathrm{SDI}_{9}\right)$, uma escarificação + uma gradagem durante nove anos $\left(E+G_{9}\right.$ ) e uma aração + duas gradagens durante nove anos $\left(A+2 \mathrm{G}_{9}\right)$. O preparo do solo, nos tratamentos pertinentes, foi executado no sentido longitudinal ao declive. Em cada um dos tratamentos, foram utilizadas uma parcela com rotação e outra com sucessão de culturas, enquanto os sistemas de cultivo rotação e sucessão foram considerados como sendo repetição no mesmo tratamento de preparo do solo. As culturas em rotação consistiram de feijão, ervilhaca, milho e aveia e, em sucessão, soja, trigo, soja e trigo. Um tratamento-testemunha, em duas repetições, constou de uma aração + duas gradagens em solo sem cultivo durante nove anos (SSC 9 ).

A área experimental recebeu, desde 1988, $525 \mathrm{~kg} \mathrm{ha}^{-1}$ de N, $1.302 \mathrm{~kg} \mathrm{ha}^{-1}$ de $\mathrm{P}_{2} \mathrm{O}_{5}$ e $1.075 \mathrm{~kg} \mathrm{ha}^{-1}$ de $\mathrm{K}_{2} \mathrm{O}$, na forma de fertilizantes químicos, distribuídos nos diversos cultivos, principalmente nos de primavera-verão. Além disso, el a foi corrigida com calcário dolomítico em outubro de 1988, com $12 \mathrm{Mg} \mathrm{ha}^{-1} \mathrm{e}$, em outubro de 1992, mais 3,5 $\mathrm{Mg} \mathrm{ha}^{-1}$ do mesmo calcário. $\mathrm{O} \mathrm{SSC}_{9}$ não recebeu calcário nem fertilizante nesse período.

Durante os cultivos de feijão e soja, foram adicionados ao solo $31 \mathrm{~kg} \mathrm{ha}^{-1}$ de $\mathrm{P}_{2} \mathrm{O}_{5}$ e $48 \mathrm{~kg} \mathrm{ha}^{-1}$ de $\mathrm{K}_{2} \mathrm{O}$, enquanto, nos cultivos de ervilhaca e trigo, os valores foram de $19 \mathrm{~kg} \mathrm{ha}^{-1}$ de $\mathrm{P}_{2} \mathrm{O}_{5}$ e $30 \mathrm{~kg} \mathrm{ha}^{-1}$ de $\mathrm{K}_{2} \mathrm{O}$. Nos cultivos de milho e soja, foram adicionados $20 \mathrm{~kg} \mathrm{ha}^{-1}$ de $\mathrm{N}$ para o milho e, para ambas as culturas, $65 \mathrm{~kg} \mathrm{ha}^{-1}$ de $\mathrm{P}_{2} \mathrm{O}_{5}$ e $95 \mathrm{~kg} \mathrm{ha}^{-1}$ de $\mathrm{K}_{2} \mathrm{O}$, além de $20 \mathrm{~kg} \mathrm{ha}^{-1}$ de $\mathrm{N}$ em cobertura para o milho. Nos cultivos de aveia e trigo, não foram aplicados fertilizantes no momento da semeadura, tendo sido aplicados $45 \mathrm{~kg} \mathrm{ha}^{-1}$ de $\mathrm{N}$ em cobertura em ambas. $\mathrm{Nas} \mathrm{SDI}_{6} \mathrm{eSDI}_{9}$, os fertilizantes foram aplicados em cobertura e a lanço no solo, tendo sido semi-incorporados na $E+G_{9}$ e incorporados ao solo na $A+2 G_{9}$.

A unidade experimental constituiu-se de uma parcela com dimensões de $22,1 \times 3,5 \mathrm{~m}$. Ela foi delimitada na extremidade superior e nas Iaterais por chapas galvanizadas cravadas $0,1 \mathrm{~m}$ no solo e, na extremidade inferior, por um sistema col etor de enxurrada, composto de uma calha para receber o material erodido conectada por um cano de PVC ao primeiro tanque, de sedimentação, situado $6 \mathrm{~m}$ abaixo da parcela. Este, por sua vez, estava ligado, por meio de um divisor de enxurrada do tipo "Geib", com nove janelas, ao segundo tanque, de armazenagem. 
A col eta das amostras de enxurrada nos tanques e o seu processamento no laboratório, para quantificar as perdas de solo e água, foram feitos seguindo o método proposto por Cogo (1978).

Durante os quatro cultivos estudados, foram col etadas e analisadas amostras de enxurradas de 51 chuvas erosivas, a saber: 13 chuvas no primeiro cultivo, 17 no segundo, 12 no terceiro e nove no quarto cultivo. A seleção das enxurradas para a col eta das amostras foi feita de acordo com o volume de chuva precipitado, adotando-se o critério de coletar amostras de enxurradas provenientes de chuvas com volumesuperior a $20 \mathrm{~mm}$. Essas chuvas, que totalizaram $1.936 \mathrm{~mm}$, representaram, em volume, $73 \%$ do total precipitado nos quatro cultivos (2.639 mm), com a seguinte distribuição relativa: $20 \%$ no primeiro cultivo, $36 \%$ no segundo, $22 \%$ no terceiro e $22 \%$ no quarto cultivo.

Após a coleta das amostras de enxurrada nos tanques para a determinação das perdas de solo e água, eram coletadas, nos mesmos tanques, duas amostras da enxurrada em cada tanque (tratamento), em frascos de vidro de $300 \mathrm{~mL}$ cada um. Destas amostras era retirada, imediatamente após a col eta, uma alíquota da água sobrenadante para, após decantação dos sedimentos, efetuar análise do $\mathrm{P}$ (Murphy \& Riley) e do K (fotômetro de chama), descritos em Tedesco et al. (1995).

As amostras dos sedimentos coletados na enxurrada em cada chuva erosiva foram secas a $60^{\circ} \mathrm{C}$ earmazenadas em potes plásticos atéo final do ciclo de cada cultura, constituindo uma amostra única dos sedimentos por cultivo. Nestas amostras, foram determinados os teores de P extraível e potássio trocável (Mehlich-1), descritos em Tedesco et al. (1995). Assim, foram determinadas as concentrações deP e $K$ na água ede $P$ extraível eK trocável no sedimento da enxurrada (ambos em $\mathrm{mg} \mathrm{dm}^{-3}$ ). As perdas de $P$ e K na água da enxurrada $\left(\mathrm{g} \mathrm{ha}^{-1}\right)$ foram calculadas pel o produto da concentração dos el ementos na água pela perda total de água, enquanto as perdas dos dois el ementos nos sedimentos ( $\mathrm{g} \mathrm{ha} \mathrm{H}^{-1}$ ), foram obtidas pelo produto da sua concentraçãonos sedimentos pela perda total de sedimentos.

Aofinal decada cultivo, foram col etadas amostras do solo na camada de $0-0,025 \mathrm{~m}$, nas quais foram determinados os teores de P extraível e K trocável, pelo método descrito por Tedesco et al. (1995).

Por meio de regressãolinear, utilizando o modelo $y=a+b x$, correlacionaram-se as perdas de água com as concentrações de P e K na água da enxurrada e as perdas de solo com as concentrações de $P$ e $K$ nos sedimentos.

\section{RESULTADOS E DISCUSSÃO}

\section{Perdas de solo e água}

As perdas de solo e água foram extraídas de Guadagnin et al . (2003), cujotrabal ho foi desenvolvido concomitantemente a este. Elas estão apresentadas com o objetivo de embasar as discussões que serão feitas adiante sobre as perdas de $\mathrm{P}$ e $\mathrm{K}$ ocorridas pela erosão hídrica.

As perdas de sol o foram maiores no $\mathrm{SSC}_{9}$ do que nos demais tratamentos, conforme esperado (Quadro 1), explicadas pelo preparo de solo

Quadro 1. Perdas de solo e água em 51 chuvas erosivas, em diferentes sistemas de manejo de um Cambissolo Húmico alumínico léptico. Média da rotação e sucessão de culturas - adaptadas de Guadagnin et al. (2003)

\begin{tabular}{|c|c|c|c|c|c|c|}
\hline Cultivo & SDI $_{6}$ & SDI 9 & $E+\mathbf{G}_{9}$ & $A+2 \mathbf{G}_{9}$ & $\mathbf{S S C}_{9}$ & $\mathbf{E I}_{30}$ \\
\hline & \multicolumn{5}{|c|}{-Perdas de solo, Mg ha-1 } & MJ $\mathrm{mm} \mathrm{ha}^{-1} \mathrm{~h}^{-1}$ \\
\hline 10 & 0,04 & 0,02 & 0,05 & 0,11 & 10,94 & 1.567 \\
\hline 20 & 0,31 & 0,34 & 1,04 & 3,98 & 56,85 & 2.950 \\
\hline 30 & 0,07 & 0,06 & 0,23 & 0,94 & 15,77 & 1.504 \\
\hline $4^{\circ}$ & 0,44 & 0,29 & 0,40 & 0,81 & 10,11 & 890 \\
\hline Média & 0,21 & 0,18 & 0,43 & 1,46 & 23,42 & 1.728 \\
\hline \multirow[t]{2}{*}{ DP } & 0,17 & 0,14 & 0,38 & 1,49 & 19,40 & 753 \\
\hline & \multicolumn{5}{|c|}{ Perdas de água, \% de chuva ${ }^{1}$} & Chuva - m³ ha-1 \\
\hline 10 & 1,0 & 1,0 & 2,3 & 3,9 & 10,5 & 3.890 \\
\hline $2^{\circ}$ & 2,0 & 6,1 & 3,7 & 7,6 & 5,9 & 7.030 \\
\hline 3० & 1,1 & 1,8 & 4,6 & 13,3 & 21,1 & 4.350 \\
\hline $4^{\circ}$ & 27,9 & 28,4 & 35,1 & 58,2 & 49,0 & 4.090 \\
\hline Média & 7,1 & 8,8 & 10,2 & 18,8 & 19,3 & 4.840 \\
\hline
\end{tabular}

$\mathrm{SDI}_{6}$ : semeadura direta com seis anos; $\mathrm{SDI}_{9}$ : semeadura direta com nove anos; $\mathrm{E}+\mathrm{G}_{9}$ : escarificação + gradagem com nove anos; $\mathrm{A}+2 \mathrm{G}_{9}$ : aração + duas gradagens com nove anos; $\mathrm{SSC}_{9}$ : solo sem cultura com nove anos; $1^{\circ}$ : feijão na rotação e soja na sucessão; $2^{\circ}$ : ervilhaca na rotação e trigo na sucessão; $3^{\circ}$ : mil ho na rotação e soja na sucessão; $4^{\circ}$ : aveia na rotação e trigo na sucessão; DP: desviopadrão. 
convencional e ausência completa de cultivo que manteve a superfície descoberta e exposta ao impacto das gotas da chuva e à enxurrada.

Dentre os tratamentos com cultivo, a $\mathrm{A}+2 \mathrm{G}_{9}$ apresentou perdas de sol o 3,4, 8,1 e 7,0 vezes maiores do que na $\mathrm{E}+\mathrm{G}_{9}$, $^{\mathrm{SDI}}{ }_{9}$ e $\mathrm{SDI}{ }_{6}$, respectivamente (Quadro 1), o que também foi verificado por Bertol (1994b), Schick et al. (2000a) e Guadagnin (2003). Tal fato é explicado pela quase que completa ausência de cobertura, baixa rugosidade superficial e maior quantidade de partículas prontamente disponíveis para o transporte, além da maior susceptibilidade do solo à erosão em sulcos na $A+2 G_{9}$, conforme constatado também por Cogo (1981) e Bertol (1995).

A SDI (média da $\mathrm{SDI}_{6} \mathrm{e} \mathrm{SDI}_{9}$ ) reduziu as perdas de solo em cerca de 55 e 87 \% em relação a $E+G_{9}$ e $A+2 G_{9}$, respectivamente, na média dos ciclos culturais (Quadro 1), concordando com Bertol (1994b), Schick et al. (2000a;) e Guadagnin (2003). Isto pode ser atribuído aos resíduos vegetais na superfície do solo, os quais dissiparam a energia cinética das gotas da chuva e da enxurrada e diminuíram a velocidade do fluxo, reduzindo também a capacidade de desagregação e de transporte da enxurrada na SDI. Além disso, a ausência do preparo nesse tratamento permitiu o aumento da consolidação do solo, aumentando sua resistência ao sulcamento pela enxurrada.

Em geral, as perdas de água seguiram a mesma tendência das perdas de solo, tendo sido menos afetadas do que estas pelo manejo (Quadro 1). A SDI (média da SDI ${ }_{6}$ e $\mathrm{SDI}_{9}$ ) reduziu as perdas de água em 2 e $11 \%$ em relação a $E+G_{9}$ e $A+2 G_{9}$, respectivamente, na média dos ciclos culturais, conforme verificado também por Cogo (1981), Bertol (1994b) eSchick et al. (2000a). I sto é explicado pelo fato de que, independentemente do sistema de manejo, o sol o apresenta um limite de infiltração de água, a partir do qual a taxa de enxurrada tende a se igualar em distintos preparos (Bertol, 1994b). O menor vol ume de água perdido na SDI (SDI ${ }_{6} \mathrm{eSDI}_{9}$ ) eE $+\mathrm{G}_{9}$ é explicado, ainda, pela maior cobertura do solo, especialmente na SDI (SDI ${ }_{6}$ e $\mathrm{SDI}_{9}$ ) e, no caso da $E+G_{9}$, também pela el evada rugosidade superficial, conforme constatado por Schick et al. (2000a) no mesmo experimento.

\section{Concentrações de P extraível e K trocável na camada de 0-0,025 m do solo}

Em geral, as concentrações de $\mathrm{P}$ e $\mathrm{K}$ na camada de $0-0,025 \mathrm{~m}$ do solo foram altas (Quadro 2), com exceção do $\mathrm{P}$ na $\mathrm{A}+2 \mathrm{G}_{9}$ e no $\mathrm{SSC}_{9}$, concordando com Eltz et al. (1989), Schick et al . (2000b) e Guadagnin (2003). I Isto é explicado principalmente pelas adubações efetuadas no solo e manutenção de resíduos vegetais (exceto no $\mathrm{SSC}_{9}$ ), cujos nutrientes e resíduos foram mantidos na superfície em virtude da ausência de preparo na SDI ${ }_{6}$ e SDI 9 e do cultivo mínimo na $E+G_{9}$. No caso da $A+2 G_{9}$, a menor concentração do elemento na superfície do sol o está relacionada com o preparo que incorporou os adubos e os resíduos e os distribuiu na camada preparada.

No caso do $\mathrm{P}$, $\mathrm{aSDI}_{6}, \mathrm{SDI}{ }_{9}$ eE $+\mathrm{G}_{9}$ aumentaram sua concentração no solo em 3,4 vezes em relação a $A+2 G_{9}$, na média dos cultivos (Quadro 2), enquanto, no caso do K, esse aumento foi da ordem de 1,6 vez, revelando que o $\mathrm{K}$ efetivamente é mais móvel no sol o e concentra-se menos na superfície do que o $\mathrm{P}$ nos preparos conservacionistas, conforme constatado também por Eltz et al. (1989) e Schick et al . (2000b). A concentração desses dois elementos na superfície do solo nos preparos conservacionistas contribuiu para aumentar seu transporte pela enxurrada, especial mente quando adsorvidos aos sedimentos.

\section{Concentrações de P eK na água da enxurrada}

As concentrações deP na água da enxurrada foram

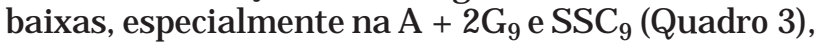
concordando com Hernani et al. (1999), Schick (1999) e Schick et al. (2000b).

Quadro 2. Concentrações de $P$ extraível e de $K$ trocável na camada de 0-0,025 $\mathrm{m}$ do solo, em diferentes sistemas de manejo durante os quatro cultivos de um Cambissolo Húmico alumínico léptico

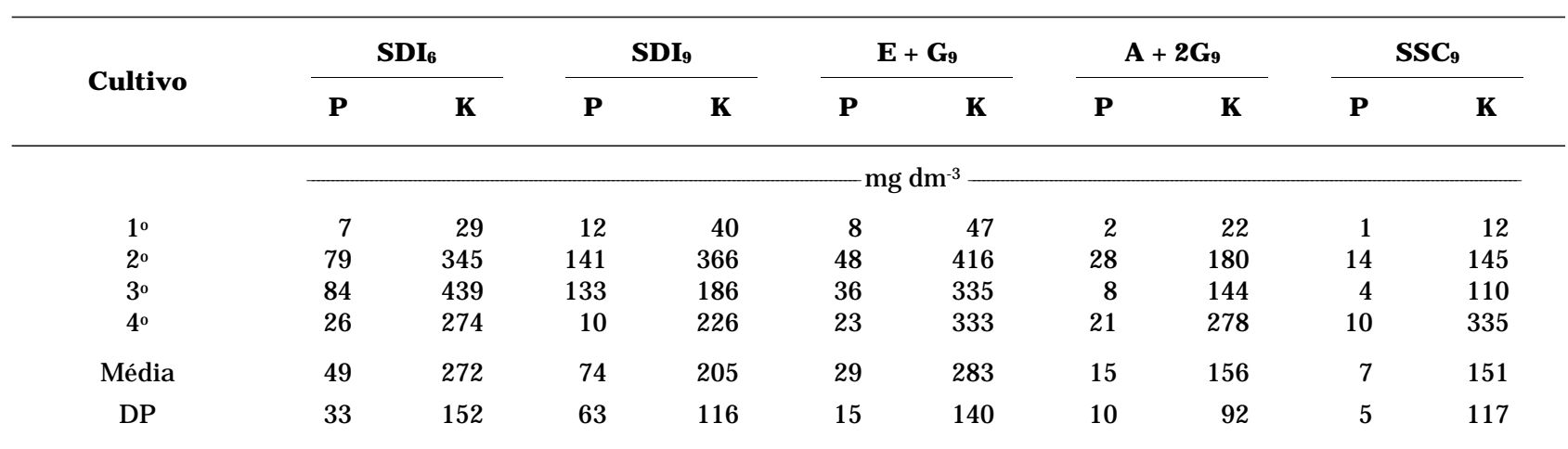

$\mathrm{SDI}_{6}$ : semeadura direta com seis anos; $\mathrm{SDI}$ : semeadura direta com nove anos; $\mathrm{E}+\mathrm{G}_{9}$ : escarificação + gradagem com nove anos; $\mathrm{A}+2 \mathrm{G}_{9}$ : aração + duas gradagens com nove anos; $\mathrm{SSC}_{9}$ : solo sem cultivo com nove anos; DP: desvio-padrão. 
Quadro 3. Concentrações de P e K na água da enxurrada, em diferentes sistemas de manejo durante os quatro cultivos de um Cambissolo Húmico alumínico léptico (média das coletas e da rotação e sucessão de culturas)

\begin{tabular}{|c|c|c|c|c|c|c|c|c|c|c|c|}
\hline \multirow{2}{*}{ Cultivo } & \multicolumn{2}{|c|}{$\mathrm{SDI}_{6}$} & \multicolumn{2}{|c|}{ SDI 9} & \multicolumn{2}{|c|}{$\mathbf{E}+\mathbf{G}_{\mathbf{9}}$} & \multicolumn{2}{|c|}{$A+2 G_{9}$} & \multicolumn{2}{|c|}{ SSC $_{9}$} & \multirow{2}{*}{ Chuva } \\
\hline & $\mathbf{P}$ & K & $\mathbf{P}$ & K & $\mathbf{P}$ & K & $\mathbf{P}$ & K & $\mathbf{P}$ & K & \\
\hline & & & & & $-m$ & -1 & & & & - & $\mathrm{mm}$ \\
\hline $1^{\circ}$ & 0,52 & 9,39 & 1,22 & 16,95 & 0,99 & 15,12 & 0,37 & 9,47 & 0,35 & 2,45 & 389 \\
\hline $2^{\circ}$ & 0,17 & 5,78 & 0,46 & 6,35 & 0,14 & 6,17 & 0,02 & 5,28 & 0,01 & 3,07 & 703 \\
\hline $3^{\circ}$ & 0,73 & 11,01 & 1,40 & 9,87 & 0,32 & 7,75 & 0,04 & 5,45 & 0,05 & 2,82 & 435 \\
\hline $4^{\circ}$ & 0,53 & 8,93 & 0,61 & 10,30 & 0,16 & 5,20 & 0,01 & 3,40 & 0,01 & 2,76 & 409 \\
\hline Média & 0,49 & 8,78 & 0,92 & 10,87 & 0,40 & 8,56 & 0,11 & 5,90 & 0,11 & 2,78 & 484 \\
\hline DP & 0,53 & 8,98 & 1,00 & 11,52 & 0,53 & 9,40 & 0,19 & 6,30 & 0,18 & 2,78 & 500 \\
\hline
\end{tabular}

$\mathrm{SDI}_{6}$ : semeadura direta com seis anos; $\mathrm{SDI}{ }_{9}$ : semeadura direta com nove anos; $\mathrm{E}+\mathrm{G}_{9}$ : escarificação+gradagem com nove anos; $\mathrm{A}+2 \mathrm{G}_{9}$ : aração + duas gradagens com nove anos; $\mathrm{SSC}_{9}$ : solo sem cultivo com nove anos; DP: desvio-padrão.

Nos preparos conservacionistas $\left(\mathrm{SDI}_{6}, \mathrm{SDI}_{9} \mathrm{e}\right.$ $\left.\mathrm{E}+\mathrm{G}_{9}\right)$, a concentração de $P$ na água da enxurrada (Quadro 3) foi 5,6 vezes maior do que nos convencionais $\left(\mathrm{A}+2 \mathrm{G}_{9}\right.$ e $\mathrm{SSC}_{9}$ ), na média dos cultivos, concordando com Schick et al. (2000b). As maiores concentrações de $\mathrm{P}$ na água da enxurrada dos preparos conservacionistas estão associadas à sua mai or concentração na superfície do sol o (Quadro 2). Isto é conseqüência dos resíduos vegetais mantidos na superfíciee das adubações fosfatadas adi cionadas sobre o solo por ocasião da implantação das culturas. Nos preparos convencionais ( $\mathrm{A}+2 \mathrm{G}_{9}$ e $\mathrm{SSC}_{9}$ ), por outro lado, a menor concentração de $\mathrm{P}$ na camada superficial do solo (Quadro 2) e, conseqüentemente, na água da enxurrada, foi devida, no caso do SSC $_{9}$, à ausência de resíduos e adubações e, no caso da $A+2 G_{9}$, à incorporação ao solo, pelo preparo, tanto dos adubos aplicados quanto dos resíduos vegetais.

As concentrações de $P$ na água da enxurrada variaram entre os cultivos (Quadro 3), tendendo, na maioria dos casos, a diminuir do início para o final dos ciclos das culturas (dados não mostrados), concordando com Guadagnin (2003). As variações entre cultivos são normais e dependem das variações dos fatores que influenciam a mineralização do el emento, especial mente daquel es relacionados com o clima, os quais influem na atividade biológica, bem como com o vol ume de chuvas preci pitadas em cada cultivo.

As concentrações de $\mathrm{K}$ na água da enxurrada foram expressivamente maiores do que as de $P$, em todos os tratamentos, concordando com Schick (1999), Schick et al. (2000b) e Guadagnin (2003). A maior concentração de $\mathrm{K}$ do que de $\mathrm{P}$ na água da enxurrada é explicada pel ofato deque este el emento se encontra em maiores concentrações no solo, além de ser mais solúvel e móvel no solo do que o P.
Nos preparos $\mathrm{SDI}_{6}, \mathrm{SDI}{ }_{9} \mathrm{eE}+\mathrm{G}_{9}$, a concentração de $K$ na água da enxurrada foi 2,2 vezes maior do que no $\mathrm{A}+2 \mathrm{G}_{9}$ e $\mathrm{SSC}_{9}$, na média dos sistemas de preparo e ciclos culturais (Quadro 3). Este comportamentoé expl icado pelas altas concentrações do elemento na camada superficial do solo (Quadro 2) nos preparos conservacionistas, decorrente das adubações e do acúmulo de resíduos vegetais na superfície. Nos preparos convencionais ( $\mathrm{SSC}_{9}$ e $A+2 \mathrm{G}_{9}$ ), as concentrações de $\mathrm{K}$ relativamente altas na água são explicadas, no caso do SSC $_{9}$, pelo elevado estoque natural deste elemento no solo e, no caso da $A+2 G_{9}$, al ém do estoque, pela incorporação dos resíduos vegetais e dos adubos ao solo pel o preparo. Os dados obtidos em relação ao K concordam com os de Schick et al. (2000b) e Guadagnin (2003).

As concentrações de $K$ na água da enxurrada variaram amplamente entre os cultivos (Quadro 3) e entre as col etas (dados não mostrados), tendendo a diminuir do início para o final dos ciclos das culturas, concordando com Guadagnin (2003). I sto é explicado do mesmo modo como para oP, discutido anteriormente.

As concentrações de $\mathrm{P}$ eK na água da enxurrada afetaram fortemente as perdas desses el ementos na água, especialmente no caso do K, cujas concentrações foram, na média dos tratamentos e cultivos, 18 vezes maiores do queas do P (Quadro 3).

\section{Concentrações de P extraível e K trocável no sedimento da enxurrada}

As concentrações de $P$ nosedimento da en xurrada (Quadro 4) foram cerca de 230 vezes maiores do que as da água (Quadro 3), na média dos tratamentos e dos cultivos, concordando com os dados de Pote et 
al. (1996), Gaschoet al. (1998) eH ernani et al. (1999), pelo fato de ser elemento praticamente não solúvel na água, mas adsorvido pelos sedimentos. Nos sedimentos, as referidas concentrações foram 5,4 vezes maiores nos preparos conservacionistas $\left(\mathrm{SDI}_{6}, \mathrm{SDI}_{9}\right.$ e $\left.\mathrm{E}+\mathrm{G}_{9}\right)$ do que nos convencionais $\left(\mathrm{A}+2 \mathrm{G}_{9}\right.$ eSSC 9 ), conforme constatado também por Schick et al. (2000b) e Guadagnin (2003), explicadas pelas maiores concentrações deste el emento na camada superficial do solo (Quadro 2), decorrentes das razões apresentadas quando da discussão das concentrações desse el emento no solo. Além disso, os sedimentos perdidos por erosão dos preparos conservacionistas provavel mente foram col oi dais na sua maioria e, portanto, com maior capacidade de adsorção de elementos químicos do que os dos convencionais, provavel mente não-coloidais na sua maioria.

No caso do $K$, as suas concentrações nos sedimentos da enxurrada (Quadro 4) foram cerca de 44 vezes maiores do que aquelas encontradas na água (Quadro 3), na média dos tratamentos e dos cultivos, conforme constatado também por Zobisch et al. (1995), Hernani et al. (1999) e Schick et al. (2000b). I Isto se deve à alta concentração deste elemento no solo (Quadro 2), decorrente principalmente da aplicação de adubos e da manutenção dos resíduos vegetais no solo, no caso dos tratamentos SDI ${ }_{6}, \mathrm{SDI}, \mathrm{E}+\mathrm{G}_{9}$ e $A+\mathrm{G}_{9}$, e, no caso do $\mathrm{SSC}_{9}$, do alto estoque natural do el emento no solo. As concentrações de K nos sedimentos foram 2,7 vezes maiores nos preparos conservacionistas $\left(\mathrm{SDI}_{6}, \mathrm{SDI}_{9}\right.$ e $\mathrm{E}+\mathrm{G}_{9}$ ) do que nos convencionais $\left(\mathrm{A}+2 \mathrm{G}_{9}\right.$ e $\left.\mathrm{SSC}_{9}\right)$, graças, principalmente, à sua maior concentração na camada superficial do solo (Quadro 2), pelas razões já discutidas anteriormente.

As concentrações de $P$ e $K$ nos sedimentos da enxurrada afetaram as perdas desses el ementos nos sedimentos, especialmente no caso do K, cujas concentrações foram, na média dos tratamentos e cultivos, 3,5 vezes maiores do queas do P (Quadro 4).

\section{Perdas totais de $\mathbf{P}$ e K na água da enxurrada}

As perdas de $P$ na água da enxurrada foram baixas (Quadro 5), concordando com Schick et al. (2000b) eGuadagnin (2003), explicadas pelas baixas concentrações do el emento na água (Quadro 3). Os sistemas de preparo de sol o conservacionistas $\left(\mathrm{SDI}_{6}\right.$, $\mathrm{SDI}_{9}$ e $\mathrm{E}+\mathrm{G}_{9}$ ) apresentaram perdas de $\mathrm{P}$ na água da enxurrada 2,6 vezes maiores do que os convencionais ( $\mathrm{A}+2 \mathrm{G}_{9}$ e $\left.\mathrm{SSC}_{9}\right)$, na média dos tratamentos e dos cultivos, influenciadas principalmente pelas maiores concentrações do elemento na água da enxurrada, já que as perdas deágua foram menores nos sistemas conservacionistas (Quadro 1). Assim, o comportamento desses dados, os quais concordam com os observados por de Richardson \& King (1995), Rhem et al. (2002) e Schick et al. (2002b), pode ser explicado pelas mesmas razões apresentadas anteriormente, utilizadas para explicar o comportamento das concentrações do $P$ na água da enxurrada. As perdas de P na água variaram entre os cultivos, de acordo com as variações nas perdas de água e com as concentrações do elemento na água da enxurrada, já discutidas.

As perdas do $\mathrm{K}$ na água da enxurrada foram el evadas (Quadro 5), concordando com Schick et al . (2000b) e Guadagnin (2003), em decorrência das elevadas concentrações do elemento na água da enxurrada (Quadros 1 e 3). Nos preparos conservacionistas $\left(\mathrm{SDI}_{6}, \mathrm{SDI}{ }_{9}\right.$ e $\left.\mathrm{E}+\mathrm{G}_{9}\right)$, as perdas deste elemento na água da enxurrada foram $13 \%$ menores do que nos convencionais ( $\mathrm{A}+2 \mathrm{G}_{9}$ eSSC $\mathrm{S}_{9}$ ), explicadas principal mente pelas maiores perdas de água ocorridas nos preparos convencionais, embora as concentrações do el emento na água da enxurrada tenham sido maiores nos preparos conservacionistas,

Quadro 4. Concentrações de P extraível e K de trocável nos sedimentos da enxurrada, em diferentes sistemas de manejo de um Cambissolo Húmico alumínico léptico (média das coletas e da rotação e sucessão de culturas)

\begin{tabular}{|c|c|c|c|c|c|c|c|c|c|c|}
\hline \multirow{2}{*}{ Cultivo } & \multicolumn{2}{|c|}{$\mathrm{SDI}_{6}$} & \multicolumn{2}{|c|}{ SDI9 } & \multicolumn{2}{|c|}{$\mathbf{E}+\mathbf{G}_{\mathbf{9}}$} & \multicolumn{2}{|c|}{$A+2 G_{9}$} & \multicolumn{2}{|c|}{ SSC $_{9}$} \\
\hline & $\mathbf{P}$ & K & $\mathbf{P}$ & $K$ & $\mathbf{P}$ & $\mathbf{K}$ & $\mathbf{P}$ & $\mathbf{K}$ & $\mathbf{P}$ & $\mathbf{K}$ \\
\hline & & & & & $r$ & $n^{-3}$ & 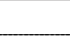 & 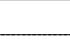 & - & 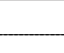 \\
\hline $1^{\circ}$ & 71 & 69 & 414 & 226 & 420 & 122 & 27 & 63 & 7 & 26 \\
\hline $2^{\circ}$ & 133 & 304 & 70 & 174 & 139 & 310 & 28 & 193 & 35 & 115 \\
\hline $3^{\circ}$ & 189 & 1.094 & 68 & 1.032 & 68 & 705 & 27 & 329 & 10 & 141 \\
\hline $4^{\circ}$ & 16 & 137 & 51 & 284 & 14 & 145 & 8 & 82 & 2 & 100 \\
\hline Média & 102 & 556 & 151 & 429 & 160 & 320 & 22 & 167 & 29 & 154 \\
\hline DP & 65 & 370 & 152 & 350 & 156 & 234 & 8 & 106 & 27 & 63 \\
\hline
\end{tabular}

$\mathrm{SDI}_{6}$ : semeadura direta com seis anos; $\mathrm{SDI}$ : semeadura direta com nove anos; $\mathrm{E}+\mathrm{G}_{9}$ : escarificação + gradagem com nove anos; $\mathrm{A}+2 \mathrm{G}_{9}$ : aração + duas gradagens com nove anos; $\mathrm{SSC}_{9}$ : solo sem cultivo com nove anos; DP = desvio-padrão 
Quadro 5. Perdas de P eK na água e de P extraível e K trocável nos sedimentos da enxurrada, em diferentes sistemas de manejo de um Cambissolo Húmico alumínico léptico (média das coletas e da rotação e sucessão de culturas)

\begin{tabular}{|c|c|c|c|c|c|c|c|c|c|c|}
\hline \multirow{2}{*}{ Cultivo } & \multicolumn{2}{|c|}{ SDI $_{6}$} & \multicolumn{2}{|c|}{ SDI9 } & \multicolumn{2}{|c|}{$\mathbf{E}+\mathbf{G}_{\mathbf{9}}$} & \multicolumn{2}{|c|}{$A+2 G_{9}$} & \multicolumn{2}{|c|}{ SSC $_{9}$} \\
\hline & $\mathbf{P}$ & $\mathbf{K}$ & $\mathbf{P}$ & K & $\mathbf{P}$ & K & $\mathbf{P}$ & K & $\mathbf{P}$ & $\mathbf{K}$ \\
\hline & \multicolumn{10}{|c|}{ g ha-1 } \\
\hline & \multicolumn{10}{|c|}{$\mathrm{Na}$ água } \\
\hline $1^{\circ}$ & 8 & 386 & 27 & 445 & 16 & 1.168 & 11 & 1.168 & 76 & 867 \\
\hline $2^{\circ}$ & 72 & 5.483 & 156 & 12.029 & 15 & 7.858 & 24 & 10.868 & 19 & 4.897 \\
\hline $3^{\circ}$ & 22 & 479 & 142 & 727 & 19 & 1.118 & 7 & 2.141 & 10 & 1.807 \\
\hline $4^{\circ}$ & 17 & 427 & 115 & 625 & 18 & 851 & 4 & 1.470 & 7 & 859 \\
\hline \multirow[t]{2}{*}{ Total } & 119 & 6.775 & 440 & 13.826 & 68 & 10.995 & 46 & 15.647 & 112 & 8.430 \\
\hline & \multicolumn{10}{|c|}{ Nos sedimentos } \\
\hline $1^{\circ}$ & 3 & 3 & 7 & 4 & 21 & 6 & 3 & 7 & 154 & 289 \\
\hline $2^{\circ}$ & 41 & 93 & 20 & 62 & 133 & 306 & 109 & 771 & 3.857 & 8.357 \\
\hline $3^{\circ}$ & 14 & 78 & 4 & 62 & 15 & 179 & 23 & 310 & 294 & 2.631 \\
\hline $4^{\circ}$ & 7 & 59 & 19 & 96 & 6 & 58 & 6 & 67 & 37 & 1.026 \\
\hline Total & 65 & 233 & 50 & 224 & 175 & 549 & 141 & 1.155 & 4.342 & 12.303 \\
\hline
\end{tabular}

$\mathrm{SDI}_{6}$ : semeadura direta com seis anos; $\mathrm{SDI}$ : semeadura direta com nove anos; $\mathrm{E}+\mathrm{G}_{9}$ : escarificação + gradagem com nove anos; $\mathrm{A}+2 \mathrm{G}_{9}$ : aração + duas gradagens com nove anos; $\mathrm{SSC}_{9}$ : solo sem cultivo com nove anos.

concordando com Hernani et al. (1999) e Schick et al. (2000b). As referidas perdas variaram entre os cultivos, em decorrência das oscilações das perdas de água e das concentrações do el emento na água, já discutidas.

\section{Perdas totais de $\mathbf{P}$ extraível e $\mathrm{K}$ trocável no sedimento da enxurrada}

As perdas de $P$ nos sedimentos da enxurrada foram baixas nos tratamentos que envolveram cultivo do solo $\left(\mathrm{SDI}_{6}, \mathrm{SDI}_{9}, \mathrm{E}+\mathrm{G}_{9}\right.$ e $\mathrm{A}+2 \mathrm{G}_{9}$ ) (Quadro 5), apesar das altas concentrações do elemento nos sedimentos da enxurrada nesses tratamentos (Quadro 4), concordando com os dados obtidos por Bertol (1994a), Schick et al. (2000b) e Guadagnin (2003). Assim, as baixas quantidades de $P$ perdido nos sedimentos foram influenciadas, principal mente, pelas baixas perdas de sol o ocorridas nesses tratamentos (Quadro 1). No caso do $\mathrm{SSC}_{9}$, a alta perda desse elemento nos sedimentos é explicada, principalmente, pela alta perda de solo, já quea concentração desse el emento nos sedimentos foi baixa.

Nos sedimentos, as perdas de $K$ foram 3,7 vezes maiores nos tratamentos que envolveram preparo do solo $\left(E+G_{9}\right.$ e $\left.A+2 G_{9}\right)$ do que naqueles sem preparo (SDI 6 e SDI 9 ) (Quadro 5), explicadas principalmente pelas maiores perdas de solo ocorridas nos tratamentos com mobilização do solo, principalmente no $A+2 G_{9}$ (Quadro 1 ), já que as concentrações de $\mathrm{K}$ nos sedimentos foram menores nesses tratamentos do que nos conservacionistas (Quadro 4), discordando de Rhem et al. (2002). As perdas de K nos sedimentos foram 20 vezes maiores nos preparos convencionais $\left(\mathrm{A}+2 \mathrm{G}_{9}\right.$ eSSC $\mathrm{S}_{9}$ ) do que nos conservacionistas (SDI ${ }_{6}, \mathrm{SDI}_{9}$ e $E+\mathrm{G}_{9}$ ) (Quadro 5), explicadas porque, na $\mathrm{A}+2 \mathrm{G}_{9}$ e $\mathrm{SSC}_{9}$, as perdas de solo foram maiores do que nos demais tratamentos (Quadro 1), cujos dados concordam com os de Zobisch et al. (1995), Hernani et al. (1999) e Schick et al. (2000b).

Os dados mostram que, em situações de longos comprimentos de rampa e, ou, el evadas inclinações de declive, as quais favorecem a enxurrada, em conjunto com sistemas inadequados de manejo do solo e na ausência de práticas conservacionistas de suporte, as perdas de $\mathrm{P}$ e $\mathrm{K}$ podem ser altas, com possíveis reflexos no empobrecimento do solo e na contaminação dos locais de deposição da erosão, fora do seu local de origem.

As perdas de água e solo apresentaram correlação negativa com as concentrações de $\mathrm{P}$ e K na água e nos sedimentos perdidos por erosão hídrica (Figura 1). Assim, na medida em que aumentaram as perdas de água e solo, diminuíram as concentrações de P e K, tanto na água quanto nos sedimentos, confirmando que, nos sistemas de manejo conservacionistas, nos quais as perdas de água e sol o são menores do que nos convencionais, a água e os sedimentos perdidos por erosão são mais concentrados em $\mathrm{P}$ e K. 
No caso do $\mathrm{P}$ eK presentes na água da enxurrada, as correlações entre as concentrações desses elementos na água e as quantidades de água perdidas foram relativamente altas. No caso do $P$ (Figura 1a), $65 \%$ da concentração do elemento na água foi dependente do volume de água perdido, enquanto, no caso do K, tal relação foi ainda maior, ou seja, 78 \% (Figura 1b). Assim, para as condições do experimento, é possível utilizar ovolume de água perdido pela enxurrada para inferir sobre a concentração desses elementos na água da enxurrada, principalmente para oK, levando-seem conta o grau de confiabilidade conferido pelos respectivos coeficientes de correlação. As correlações entre as perdas de solo e as concentrações de $\mathrm{P}$ e K nos sedimentos perdidos por erosão foram muito baixas, indicadas pelos baixos valores de $\mathrm{R}^{2}, 0,34$ para o $\mathrm{P}$ (Figura 1c) e 0,35 para o K (Figura 1d). Nesse caso, provavelmente é necessário maior número de dados, obtidos em maior período de tempo, para descrever melhor essa relação, dada a alta variabilidade das perdas de solo, tanto entre tratamentos quanto entreépocas. Essa variabilidade foi menor no caso das perdas de água.
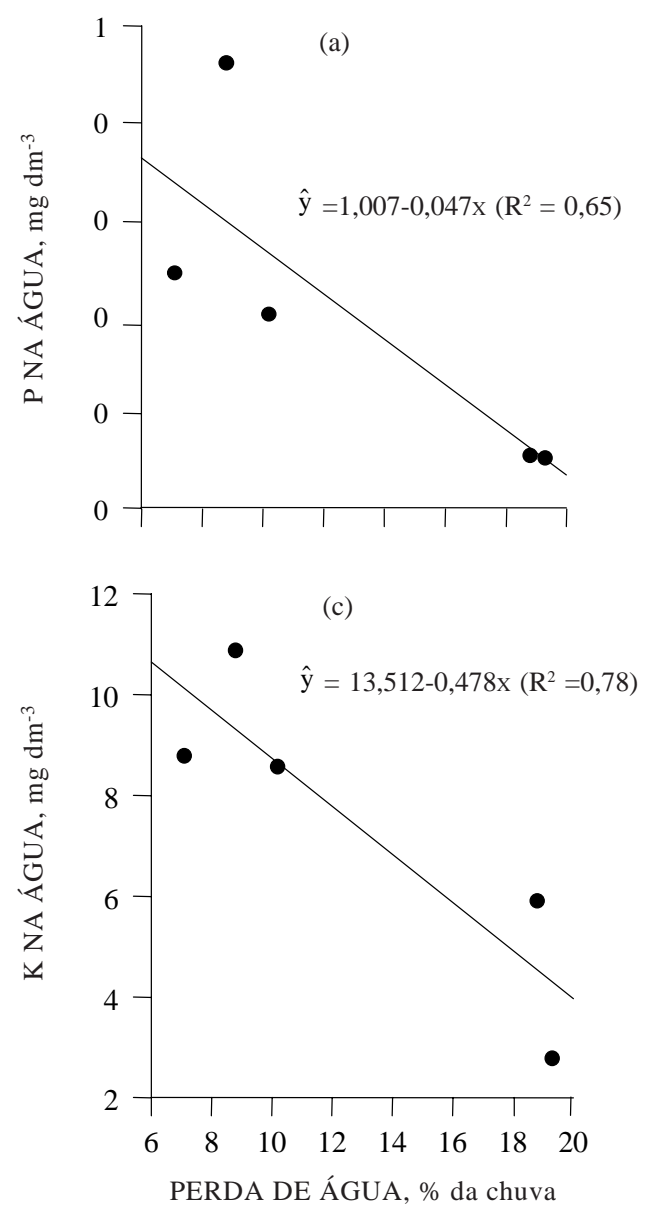

\section{CONCLUSÕES}

1. As concentrações de P e K foram maiores nos sistemas de manejo de sol o conservacionistas do que nos convencionais, tanto na água quanto nos sedimentos da enxurrada, sendo, ainda, substancialmente maiores nos sedimentos do que na água da enxurrada.

2. As perdas totais de $\mathrm{K}$ foram maiores na água do que nos sedimentos da enxurrada, com exceção do manejo $S_{S C}$. Com relação às perdas de $P$, apenas nos manejos $\mathrm{SDI}_{6} \mathrm{eSDI}_{9}$, elas foram maiores na água do que nos sedimentos.

3. No caso da água da enxurrada, as perdas totais de $\mathrm{P}$ foram maiores nos manejos $\mathrm{SDI}_{6}$ e SDI 9 , enquanto as perdas de $\mathrm{K}$ variaram com os preparos conservacionistas econvencionais, sem apresentarem uma tendência clara.

4. No caso dos sedimentos da enxurrada, as perdas totais de $\mathrm{K}$ foram menores nos preparos conservacionistas, mas as de $\mathrm{P}$ foram menores apenas nos manejos $\mathrm{SDI}_{6}$ e SDI 9 .
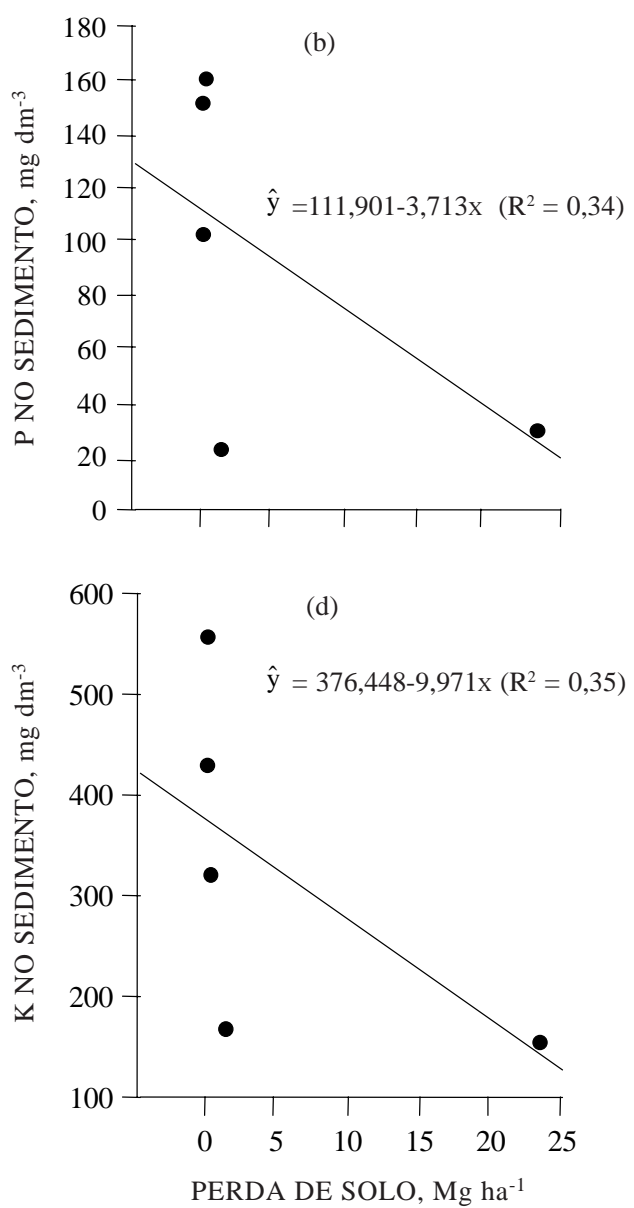

Figura 1. Relação das perdas de água com o $P$ na água (a) e com o $K$ na água (b) e das perdas de solo com o P no sedimento (c) e com o K no sedimento (d) (média de quatro cultivos). 
5. As concentrações de $\mathrm{P}$ e $\mathrm{K}$ na água da enxurrada foram descritas pelo volume de água perdida por erosão hídrica, por meio de modelo de regressão linear simples, sendo a relação negativa; no caso da relação com as perdas de sol o por erosão hídrica, as concentrações desses el ementos nos sedimentos apresentaram relação linear muito baixa, também negativa.

\section{LITE RATURA CITADA}

BERTOL, I. Perdas de nutrientes por erosão hídrica em diferentes sistemas de manejo de solo sob rotação de culturas. Univ. Des., 2:174-184, 1994a.

BERTOL, I. Erosão hídrica em Cambissolo Húmico distrófico sob diferentes preparos do solo e rotação de cultura. R. Bras. Ci. Solo, 18:267-271, 1994b.

BERTOL, I. Comprimento crítico de declive para preparos conservacionistas de solo. Porto Alegre, Universidade Federal do Rio Grande do Sul, 1995. 185p. (Tese de Doutorado)

BERTOL， I.B.; MELLO, E.L.; GUADAGNIN， J.C.; ZAPAROLLI, A.L.V. \& CARRAFA, M.R. Nutrient losses by water erosion. Sci. Agr., 60:581-586, 2003.

COGO, N.P. U ma contribuição à metodologia de estudo das perdas de erosão em condições de chuva natural. I. Sugestões gerais, medição dos volumes, amostragem e quantificação de solo e água da enxurrada (1 ${ }^{a}$ aproximação). In: ENCONTRO NACIONAL DE PESQUISA SOBRE CONSERVAÇÃO DO SOLO, 2., Passo Fundo, 1978. Anais. Passo Fundo, EMBRAPACNPT, 1978. p.75-98.

COGO, N.P. Effect of residue cover, tillage induced roughness, and slope length on erosion and related parameters. West Lafayette, Purdue University, 1981. 346p. (Tese de Doutorado)

DANIEL, T.C.; SHARPLEY, A.N.; EDWARDS, D.R.; WEDEPOHL, R. \& LEMUNYON, J.L. Minimizing surface water eutrophication from agriculture by phosphorus management. J . Soil Water Conserv., 40:3038, 1994.

ELTZ, F.L.F.; PEIXOTO, R.T.G. \& J ASTER, F. Efeitos de sistemas de preparos do solo nas propriedades físicas e químicas de um Latossolo Bruno álico. R. Bras. Solo, 13:259-267, 1989.

FAVARETTO, N. Gypsum amendment and exchangeable calcium and magnesium related to water quality and plant nutrition. West Lafayette, Purdue University, 2002. 150p. (Tese de Doutorado)

GASCHO, G.J .; WAUCHOPE, R.D. \& DAVIS, J .G. Nitratenitrogen, soluble, and bioavailable phosphorus runoff from simulated rainfall after fertilizer application. Soil Sci, Soc. Am. J ., 62:1711-1718, 1998.

GUADAGNIN, J.C. Perdas de nutrientes e carbono orgânico pela erosão hídrica, em um Cambissolo Húmico alumínico léptico submetido a diferentes sistemas de preparo e cultivo do sol o. Lages, Universidade do Estado de Santa Catarina, 2003. 142p. (Tese de Mestrado)
GUADAGNIN, J .C.; BERTOL, I.; CASSOL, P.C. \& AMARAL, A.J. Perdas de nitrogênio por erosão hídrica em diferentes sistemas de manejo em um Cambissolo Húmico alumínico léptico. R. Bras. Ci. Solo, 2003. (No prelo)

HERNANI, L.C.; KURIHARA, C.H. \& SILVA, W.M. Sistemas de manejo do sol o e perdas de nutrientes ematéria orgânica por erosão. R. Bras. Ci. Solo, 23:145-154, 1999.

KING, K.W.; RICHARDSON, C.W. \& WILLIAMS, J.R. Simulation of sediment and nitrate loss on a Vertissol with conservation practices. Trans. Am. Soc. Agric. Eng., 6:21392145, 1996.

LANGDALE, G.W.; LEONARD, R.A. \& THOMAS, A.W. Conservation pactices effects on phosphorus losses from Southern Piedmont watersheds. J. Soil Water Cons., 40:157-160, 1985.

MELLO, E.L. Erosão hídrica em diferentes sistemas de manejo do sol o sob chuva simulada. Lages, U niversidade do Estado de Santa Catarina, 2002. 88p. (Tese de Mestrado)

MCISAAC, G.F.; MITCHELL, J .K. \& HIRSCHI, M.C. Dissolved phosphorus concentrations in runoff from simulated rainfall on corn and soybean tillage systems. J . Soil Water Conserv., 4:383-387, 1995.

POTE, D.H.; DANIEL, T.C. \& SHARPLEY, A.M. Relating extractable soil phosphorus to phosphorus losses in runoff. Soil Sci. Soc. Am. J ., 60:855-859, 1996.

RHEM, G.; LAMB, J .; SCHMITT, M.; RANDAL, G. \& BUSMAN, $L$. Agronomic and Environmental managemenent of phosphorus. University of Minnesota. <http://www. scirus.com. > acesso em 20 de set. 5p. 2002.

RICHARDSON, C.W. \& KING, K.W. Erosion and nutrient losses from zero tillage on a clay soil. J . Agric. Eng. Res., 61:8186, 1995.

SCHICK, J. Erosão hídrica em Cambissolo Húmico álico submetido a diferentes sistemas de preparo e cultivo do solo. Lages, Universidade do Estado de Santa Catarina, 1999. 114p. (Tese de Mestrado)

SCHICK, J .; BERTOL, I.; BATISTELA, O. \& BALBINOT J r., A.A. Erosão hídrica em Cambissolo Húmico alumínico submetido a diferentes sistemas de preparo e cultivo do solo: I. Perdas de sol o eágua. R. Bras. Ci. Sol o, 24:427-436, 2000a.

SCHICK, J .; BERTOL, I.; BALBINOT J r., A.A. \& BATISTELA, O. Erosão hídrica em Cambissolo Húmico alumínico submetido a diferentes sistemas de preparo e cultivo do solo: II. Perdas de nutrientes e carbono orgânico. R. Bras. Ci. Solo, 24:437-447, 2000b.

SEGANFREDO, M.L.; ELTZ, F.L.F. \& BRUM, A.C.R. Perdas de solo, água e nutrientes por erosão em sistemas de culturas em plantio direto. R. Bras. Ci. Solo, 21:287-291, 1997.

TEDESCO, M.J .; GIANELLO, C.; BISSANI, C.A.; BOHNEN, H. \& VOLKWEISS, S.J . Análise de solos, plantas e outros materiais. 2.ed. Porto Alegre, Universidade Federal do Rio Grande do Sul, 1995. 174p.

ZOBISCH, M.A.; RICHTER, C.; HEILIGTAG, B. \& SCHLOTT, R. Nutrient losses from cropland in the Central Highlands of Kenya due to surface runoff and soil erosion. Soil Till Res., 33:109-116, 1995. 